China was the subject of another interesting "Economic Glaciology" paper by J. S. Wu, who claimed that coarse-grained, exceptionally rich placer deposits are associated with crevasses in glaciated rock and in kettle-moraines, and that these are distinguishable from finer-grained, well sorted glaciofluvial placer deposits. Glacially controlled Pleistocene changes of sea-level were the subject of a number of contributions.

In several excursions before and after the meeting geomorphological features of glacial origin were examined. Particular attention was paid to this subject in the geomorphological excursion across England and Wales conducted by Professors S. W. Woolridge and A. Austin Miller.

The universal opinion was that this Congress, the first for eleven years, was an outstanding success, both from the point of view of organization and of scientific achievement. It was evident, too, from cornments of those attending excursions, that interest in glaciological problems was widespread. Glaciology has always formed an integral part of Earth Sciences and in spite of increasing specialization it is to be hoped that in future Congresses consideration will be given to the allocation of a special section to include papers on glaciological subjects.

University College, London

S. E. Hollingworth

\title{
ADVANCE OF THE FRANZ JOSEF GLACIER, NEW ZEALAND
}

REPORTS have reached England of an advance of this glacier during r 948 of about $18 \mathrm{~m}$. a week It had been receding for some fifteen years. The surface appeared to be more than usually broken as though the ice were piling up. At the observed rate of advance it is calculated that it would take about two years to reach its 1932 forward limit.

The glacier is some $22 \mathrm{~km}$. long with a mean inclination of about I I degrees. It must be one of the fastest moving glaciers of temperate regions; a speed as high as $15 \mathrm{~m}$. a day is said to have been measured by Mr. A. Harper in 1894 .

The surface of the Fox Glacier is reported to be rising some distance from its end, so that it, too, may be advancing soon. Further reports will be awaited with interest if the advance of New Zealand glaciers becomes general. It is hoped that authoritative information will be forthcoming as that at present available has been obtained from lay sources.

\section{O B I T U A R Y}

Dr. Vaughan Cornish, who died in the spring of 1948 , was perhaps best known for his writings on waves. 'This led him to the study of the phenomena of sand dunes and later to an investigation of snow waves and snow drifts, and finally to his valuable work Waves of Sand and Snow and the Eddies which make them (London, I914).

Dr. Oscar Edward Meinzer, President of the American Geophysical Union, died suddenly in June I948. Of his many important works perhaps that best known to glaciologists was his editorship of Physics of the Earth-IX. Hydrology (New York, 1942).

An appreciation of François E. Matthes, who died on $2 \mathrm{I}$ June 1948, and whose death was briefly announced in the last number of this Journal, will be found on p. 295 of the present issue. 